\title{
POTENTIAL BEHAVIOURAL ISSUES EXPOSED BY ADOLESCENTS DUE TO EXCESSIVE INTERNET GAMING HABITS: A LITERATURE REVIEW
}

\author{
Ms. Rawindar Kaur* | Dr. Ramandeep Kaur Dhillon** \\ *Ph.D. Scholar, Himalayan University, Itanagar, Arunachal Pradesh, India. \\ **Research Supervisor, Himalayan University, Itanagar, Arunachal Pradesh, India. \\ DOI: http://doi.org/10.47211/trr.2021.v07i01.011
}

\section{ABSTRACT:}

Internet Gaming addiction is an undeniably common issue, which can have serious outcomes in influenced youngsters and in their families. The standard of conduct is of adequate seriousness to bring about critical disability in close to home, family, social, instructive, word related or other significant spaces of working. The example of gaming conduct might be persistent or roundabout and intermittent. The gaming conduct and different highlights are ordinarily clear over a time of no less than a yearfor a conclusion to be allotted, alb eit the necessary term might be abbreviated if all analytic prerequisites are met and side effects are serious. The gathered evidences brought that such additions created behavioural issues among adolescents and often researchers brought that such addicted person have behavioural problems such as short temper, ag gression, conduct disorders, obsessive compulsive disorders, irritation, depression. Researchers strongly believe that internet gaming addition is a serious problem among youths and should be treated on priority.

Key words: Internet Gaming Addition; behavioural disorders; adolescents

\section{AUTHORS}

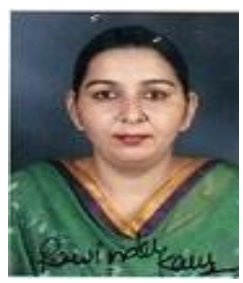

Author Ms. Rawindar Kaur is Ph.D. Scholar at Himalayan University, Itanagar, Arunachal Pradesh, India \& Nursing Officer, MKH Hospital Patiala Punjab, India.

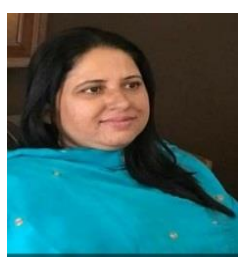

Author Dr. Ramandeep Kaur Dhillon is Research Guide at Himalayan University, Itanagar, Arunachal Pradesh, India. 


\section{INTRODUCTION:}

Innovation is on driving seat in this century; subsequently it appears to be difficult to stay away from it and to be straightforward innovation is making our daily routines substantially more agreeable and simpler to experience. Numerous advancements are gifts to human existence and when we talk about cell phone and internet providers then this gift has diverse level. Across the world individuals are appreciating administration of cell phones and web offices. Greater part of things is getting shape through on the web and helpful by making it accessibility through our wireless. The re are numerous models which are common as a significant change in light of cell phones progressions and internet providers like banking, schooling and wellbeing. At the point when we check colossal benefit of cell phone and web then one secret truth is ad ditionally follow us and that will be that will offer every assistance on portable through online mode make ourselves addicts to the se advances in light of the fact that for each and all that we are subject to these advances. (1)

Dependency on online gaming is also cause for sleep alterations because the victims majority time of day and night will go in watching mobile phone and ultimately this compromises their sleep hours as well. And being health science professionals, we are very much aware about losingadequate sleep will fur th er compromise the immunity status of individual. In a descriptive survey study, where 1000 participants participated has divulged that samples were not onlycomplained of not feelinggood when theyare away from the ir mobile device which made them to remain away from playing online with internet friends but they feel annoyed and uncomfortable when their associate tried to see their text. (2)

Across the world youth is confronting internet gaming reliance; which not just purpose physical, me ntal and social impact on them yet additionally hurt their relational abilities, scholarlyabilities and other ability. In dian youth is likewise not a special case of this pattern. Investing high measure of energy with internet games makes physical, mental and social issuesyet in addition it is an incredible test towards country's improvement as youth is consistentlyan extraordinary expectation for any country. Youth considered fu tu re labour force and when high measure of youth engaged with web gaming dependence then, at that point it's consistently an extraordinary worry to fix the circumstance. The problem arises when the person become over dependent on this and start bargain with other very important tasks, and doing th is is creating harmful effects on he alth of person. (3)

United States of America has figures that on daily basis in an around 9 to 15 million are engaging in online activities. Current statistic is suggesting that every quarterly this increase with $25 \%$ additional. In another developed country at Greece approximately $8.2 \%$ of total population found internet addicted, in which majority are belong to male gender engage with online game play. In Greece as well every year the figure goes high with $25 \%$ of rate. In South Korea $11 \%$ of school going children found at risk for on line gaming addiction. In among top five countries who use internet gaming India fall at number two and along with China, USA, Brazil and Japan constituted top internet users. (4-7)

One study concluded that Internet gaming disorder, interpreted broadly as exc essive use of online games despite negative consequences, affects a small subset of the population exposed to online games, and does not appear to have increased in prevalence to the extent that internet usage has increased. Fin dings call for deeper research with longitudinal designs and directly comparable definitions of IGD, to understand how this disorder may function as an independent clinical problem to inform diagnostic and treatment efforts. (8)

India falls as one of attractive online bazar for world, at present having 4600 lakh users who re gularly using online activities made India at 2 nd position after China. This figure is forecasted as 6358 lakh users by the end of year 2021. India witnessed the increased use of internet gaming facilities in last 4 year s. Inter net ga ming accessibility has reached too deep in society, from urban to town to rural. Gender wise statistic is refle cting man dominating figures where $71 \%$ of men are engaged with online gamesin compare to it wome has only $29 \%$ internet playing engagement. In last few years after demonetization the use of mobile and internet service has jumped to significant level. (9)

These issues are instigating the researcher to gather all possible evidences about seriousness of internet gaming disorders and its impact on adolescent's behaviour.

\section{MATERIALS AND METHODS:}

The literature review was designed as a review study, here, evidences we re gatheredabout inte rn et ga ming addiction and its impact on behavioural responses of adolescents. A systematic electronic search was u sed to identify number of studies carried out on internet gaming addiction and its behavioural impact on adolescents. The original research papers were only included in study. The following electronic databases are searched: ProQuest, Embase, PubMed, Psych ARTICLES, EBSCO, Research Gate, EORTC, Scopus, Educational Re sources Information Centre (ERIC), and Allied Health Literature (CINHAL). The existing literatures were very systematically opted to recruit into this narrative review. 


\section{INCLUSION CRITERIA}

1. The research paper only which directly involved internet gaming addiction.

2. The paper which is easily accessible online and full text available.

3. The studies which are completed in English language.

4. Articles included from the year 2010.

\section{EXCLUSIONCRITERIA}

1. Poor quality journal publications.

2. The research study which is published in without ISSN number journals.

3. The research studies which are not available on journal database.

4. The research studies in which onlyabstract is available.

5. The studies which are published in local language.

\section{RESULTS AND DISCUSSION:}

A total 206 articles were received from search engines from those 106 articles were excluded bases on exclusion criteria. So total retrieved articles were 100 amongall 45 duplicate articles, 18 No full text available, 4 not relevant and 10 abstracts were excluded. Final retrieved articles were 23; among them 13 full articles were excluded based on inclusion criteria. Finally, 10 articles we re included in the review.

There were evidences that researches organized in view to understand the level of internet gaming addiction. Doris X.Y. Chia and Melvyn W.B. Zhang (2020) has distributed their exploration paper as named as A Checking Survey of Psychological Predisposition in Web Fixation and Web Gaming Problems. Here scientist have attempted a checking audit and articles were distinguished utilizing a pursuit through the accompanying data sets: PubMed, MEDLINE, and PsycINFO. Six articles were distinguished. There were contrasts in the techniques for discovering whether an individual has a basic Web or gaming habit, as a few unique instruments have been utilized. Concerning the qualities of the intellectual predisposition appraisal task used, the most well-known errand utilized was that of the Strop task. Of the six recognized investigations, five have given proof archiving the presence of psychological inclinations in these issues. Just one examination has inspected in tellectual predisposition adjustment and offered help for its viability. While a few investigations have given primer discoveries reporting the presence of intellectual predispositions in these issues, there stays a requirement for additional examination assessing the viability of inclination adjustment, just as the normalization of the analytic devices and the assignment standards utilized in the appraisal. (10)

Nahyun Kim et al (2020) has distributed their exploration paper as named as Connections of web gaming motivations to natural markers and hazard of web gaming enslavement in Koreanjuvenile male game clie nts. Scientists utilized a multi-stage cross-sectional plan inclu ding singular meetings; centre gathe ring conversation; and elucidating, near examination. Fifteen Korean young adult male webgamers partook in singular meetings and eight took part in a centre gathering pointed toward distinguishing explanations behind web gaming. Utilizing the recognized gaming reasons from these sources we studied 225 juvenile game clients utilizing a self-report survey. Members gave blood tests to appraisal of norepinephrine (NE) and serum cortisol. Re sults recognized four significant classifications of web gaming reasons: diversion, coexisting with companions, stress alleviation, and constant gaming. The constant gathering showed essentially more serious danger of IGA than different gatherings $(p<.001)$ and the most minimal plasma NE levels $(p=.035)$, perhaps demonstrating an adjustment in autonomic capacity. Study reasoned that medical services supplier are urged to evaluate teenagers for unnecessary web gaming and to intercede with the individuals who report ongoing gaming practices. (11)

loanna Mylona et al (2020) distributed their writing survey in title of The Effect of Web and Video Gaming Dependence on Young Adult Vision: An Audit of the Writing. Creators have led broad writing audit and referenced that the most recent exploration concentrates on the effect of computerized screen e m powere $d$ gadgets on juvenile vision considering the expanding reports of web dependence and gaming issue while referring to positive discoveries of videogaming on vision to furnish a reasonable methodology and help with order, determination and treatment, while giving bearings to future examination. Creators brought the end that whether utilizing web access at higher measure of playing computer game for higher sum both keep adverse consequence on eye vision of teenagers. (12)

Maria Waris Nawaz et al (2020) has distributed their paper of Effect of PUBG Game Fixation on Friendly Disengagement and Narcissistic Inclinations among Gamers. Creators have intended to investigate the relationship of PUBG game dependence with narcissistic inclinations and social separation in gamers. For th is relationship study-based examination the information was advantage ouslygathered from PUBG gamers ( $N=$ 101) age going from 13-30years through online reaction strategy. The instruments included Web based Game Compulsion Scale, Narcissistic Character Stock and Proportions of Social Segregation for testing the 
speculation. As indicated by the yielded results, a brilliant unwavering quality of the se actions was set up. The outcomes likewise demonstrated that web-based game habit, social separation and narcissistic propen sities among PUBG game players are contrarilyconnected (<.05). It was presumed that internet games do convey positive parts of improving social abilities and associations among the players, while assisting them with displaying practices and feelings that are not sound with narcissistic inclinations. (13)

Céline Bonnaire et al (2019) has distributed their examination paper as named as Why and how to remember guardians for the treatment of teenagers introducing Web gaming problem? Present investigation me ant to grow treatment hypothesizing and mediation approaches for experts working with often life changing practices of unreasonable Web gaming. This investigationaddresses that the reasoning for a foundational conceptualization of IGD and a helpful methodology that objectives different units or subsystems. The IGD treatment program depends on the science-upheld multidimensional family treatment approach (MDFT). Following treatment improvement work, the MDFT approach has been adjusted for IGD. The examination imparted that Fundamental science formative exploration can educate conceptualization regarding IGD and a foundational rationale model of mediation and change. (14)

Jooyeon Park et al (2018) has distributed their examination paperas named as He reditary relationship of human Corticotrophin-Delivering Chemical Receptor 1 (CRHR1) with Web gaming dependence in Korean male youths. This examination planned to explore the relationship between Internet Gaming Addiction (IGA) and stress-related hereditary variations. This cross-sectional investigation was directed with 230 male se condary school understudies in a South Korean city. Results imparted that having the AA genotype and an allele of the CRHR1 quality ( $r$ 28364027) was related with higher chances of having a place with the IGA member bunch ( $p$ $=.016$ and $p=.021$, individually) than to the non-IGA bunch. Creators demonstrated that polymorphism of the CRHR1 quality may assume a significant part in IGA defencelessness in the Korean young adult male populace. These discoveries give a defence and establishment to additional examination of hereditary variables identified with IGA. (15)

Chang-hyun Park et al (2018) has distributed their examination paper as named as Adjustments in the association geography of cerebrum underlying organizations in Web gaming dependence. Specialist applied organization examination to dispersion weighted X-ray information of 102 gaming people and 41 non-ga ming solid people to look for changes in the little world geography of cerebrum underlying organizations in IGA. The association geography of mind primary organizations changed to the course of ir regular ge ography in the gaming people, independent of whether they were determined to have Web gaming problem. Moreover, when creators recreated foc used on or untargeted assaults on hubs, the association geography of the gaming people's cerebrum primary organizations underno assaults was practicallyidentical to that of the non-gaming solid people's mind underlying organizations under designated assaults. Modifications in association geography give some insight that Web gaming dependent cerebrums could be pretty much as strange as minds experiencing designated harm. (16)

Andrew K. Przybylski et al (2017) has distributed their exploration paper as named as We b Gaming Issue: Examining the Clinical Importance of Another Wonder. They have assessed the period pervasivene ss of we $b$ gaming issue's potential mental issue utilizing APA direction, analysed the legitimacy of its proposed mar kers, assessed unwavering quality diversely and across sexes, contrasted it with best quality level exa mination on betting dependence and issue gaming, and assessed its effect on physical, social, and psychological well-being. Consequences of study uncovered that Among the individuals who messed around, more than 2 out of 3 didn't report any manifestations of Web gaming problem, and discoveries showed that a little extent of everybody (somewhere in the range of $0.3 \%$ and $1.0 \%$ ) may fit the bill for a possible intense analysis of Web gaming issue. Correlation with betting problem uncovered that Web based games might be fundamentally less habit-forming than betting and also dysregulating as electronic games all the more for the most part. Study pre sumed that Web gaming issue to game commitment was solid, howeverconnections to physical, social, and e motional well-being results were determinedlyblended. (17)

Amy Slater et al (2017) has distributed their exploration paper as named as Something other than A pie ce of game? An Exploratory Examination of the Effect of an Appearance-Zeroed in Web Game on Self-perception and Vocation Goals of Little youngsters. Current examination inspected the effect of an appearance-zeroed in Web game on young ladies' self-perception and profession discernments and goals. Eighty English young ladies matured 8-9 years were haphazardly doled out to play an appearance-engaged or a non-appearance engage d game for 10 minutes. Young ladies in the appearance engaged game condition showed more prominent body disappointment contrasted with the control condition. Kind of game didn't affect young ladies' apparent ability to do different positions. Nonetheless, young ladies who played the appearance-cantered game detailed a more prominent inclination for female vocations contrasted with the benchmark group. This gives 
fundamental proof that appearance-cantered Web games might be hindering to little youngsters' selfperception and desires. The investigation inferred that Web games ought to be remembered for our thought of persuasive directives for young ladies. (18)

Vandana Chauhan et al (2017) have distributed their examination article with title as Web Dependence among Youths. Creators of this investigation uncovered that a large portion of the members utilizes web for visiting, downloading and listening music/video and for study. Most normal locales utilized by them are Facebook and WhatsApp. Result shows that the greater part of the members was better than expected clients of web. It ought to be the duty of guardians to control the utilization of web by directing their youn gster s to fore stall difficulty of web, for example, abuse of web and fixation of web that do keep undesired impact on physical and mental part of person. (19)

\section{CONCLUSION:}

After in-depth document search in line with understanding about internet gaming addiction and its impact on behaviour of adolescents. Internet Gaming Disorder (IGD), which is an underlying symptom classified as a behavioural addiction disorder, has many related social problems that have garnered the bulk of atte $n$ tion in recent research. The psychological/ behavioural mechanism is getting clear that IGA is creating number of psychological issues among adolescents. The core symptoms of IGD are that patients are of the direct impairment of their social functioning due to online gaming but are unable to control their game -playing behaviour. So, it's important for health researcher that they should take up such research with keeping intervention to control this deviation.

\section{ACKNOWLEDGEMENT:}

We are grateful to the All-Mighty God for this great blessing throughout this endeavour.

Any accomplishment requires the effort of many people. We feel it is a great privilege to express ourheartfe lt thanks and gratitude to all who directly or indirectly have given valuable guidance and timely suggestion throughout this dissertation work. Quality always makes difference through its generosity, richness, kin d ness and intelligence.

$\begin{array}{ll}\text { Source of Funding: } & \text { Self-funded project } \\ \text { Conflict of Interest: } & \text { Nil }\end{array}$

\section{REFERENCES:}

1. Yasan Ak N, Yildirim S. Nomophobia Among Undergraduate Students and Its Link to Mobile Learning. EDULEARN18 Proc. 2018;1(October):3018-25.

2. Davey S, Davey A. Assessment of smartphone addiction in Indian adolescents: A mixed method study by systematic-review and meta-analysis approach. Int J Prev Med. 2014;5(12):1500-11.

3. Amit Malviya1, Sanjay Dixit2, Harish Shukla3, Ankita Mishra4, Abhineet Jain4 at. a study to evaluate internet addiction disorder among students of a medical college and associated hospital of ce $n$ tral. 2014;5(1):93-5.

4. Clement J. Number of internet users worldwide 2019, by region [Internet]. Statista. 2020. p. 3. Available from: https://www.statista.com/statistics/249562/number-of-worldwide-internet-users-byregion/

5. Clement J. Global internet user penetration 2014-2021 [Internet]. Statista. 2019. p. 2. Available from: https://www.statista.com/statistics/325706/global-internet-user-penetration/

6. Clement J. Countries with the highest number of internet users 2019 [Internet]. Statista. p. 3. Available from: https://www.statista.com/statistics/262966/number-of-internet-users-in-selectedcountries/

7. Clement J. Most common languages used on the internet 2020 [Internet]. Statista. p. 4. Available from: https://www.statista.com/statistics/262946/share-of-the-most-common-languages-on-theinternet/

8. Feng W, Ramo DE, Chan SR, Bourgeois JA. Internet gaming disorder: Trends in prevalence 1998-2016. Addict Behav. 2017; 75:17-24.

9. Diwanji S. Mobile phone internet users in India 2015-2023 [Internet]. Statista. 2020. p. 2. A vailable from: https://www.statista.com/statistics/558610/number-of-mobile-internet-user-in-india/

10. Chia DXY, Zhang MWB. A scoping review of cognitive bias in internet addictionand inte rn et gaming disorders. Int J Environ Res Public Health. 2020;17(1):1-11.

11. Kim N, Kim MJ, Hughes TL, Kwak H, Kong ID. Relationships of internet gaming reas ons to biological indicators and risk of internet gaming addiction in Korean adolescent male game users. BMC Psychiatry. 2020;20(1):1-8. 


\section{ARTICLES}

12. Mylona I, Deres ES, Dere GDS, Tsinopoulos I, Glynatsis M. The Impact of Internet and Vide ogaming Addiction on Adolescent Vision: A Review of the Literature. Front Public Heal. 2020;8(March):1-6.

13. Nawaz MW, Nadeem T, Rao SL, Fatima T, Shoaib S. Impact of PUBG Game Addiction on Social Isolation and Narcissistic Tendencies among Gamers. Asian J Soc Sci Manag Stud. 2020;7(3):166-72.

14. Bonnaire C, Liddle HA, Har A, Nielsen P, Phan O. Why and how to include parents in the treatment of adolescents presenting Internet gaming disorder? J Behav Addict. 2019;8(2):201-12.

15. Park J, Sung JY, Kim DK, Kong ID, Hughes TL, Kim N. Genetic association of human CorticotropinReleasing Hormone Receptor 1 (CRHR1) with Internet gaming addiction in Korean male adolescents. BMC Psychiatry. 2018;18(1):1-10.

16. Park C hyun, Chun JW, Cho H, Kim DJ. Alterations in the connection topology of brain structural networks in Internet gaming addiction. Sci Rep. 2018;8(1):1-9.

17. Przybylski AK, Weinstein N, Murayama K. Internet gaming disorder: Investigating the clinical relevance of a new phenomenon. Am J Psychiatry. 2017;174(3):230-5.

18. Slater A, Halliwell E, Jarman H, Gaskin E. More than Just Child's Play? An Experimental Investigation of the Impact of an Appearance-Focused Internet Game on Body Image and Career Aspirations of Young Girls. J Youth Adolescent. 2017;46(9):2047-59.

19. Chauhan MV, Buttar DBK, Singh MR. Internet Addictionamong Adolescents. Int J Trend Sci Res Dev. 2017; Volume-1(Issue-6):395-8. 